\title{
Continuous positive airway pressure for sleep apnoea/hypopnoea syndrome: usefulness of a 2 week trial to identify factors associated with long term use
}

G Popescu, M Latham, V Allgar, M W Elliott

\begin{abstract}
Background-The sleep apnoeal hypopnoea syndrome (SAHS) is common and treatment with continuous positive airway pressure (CPAP) is effective. However, not all patients can cope with the demands of using mask positive pressure. Compliance can be improved with an intensive educational programme and patient support, but this is not practical in most centres given the large numbers of patients coming forward for treatment. Several studies have evaluated correlations between various parameters at diagnosis in order to anticipate patients' behaviour and to avoid the social and health implications of undertreated SAHS. We have evaluated the use of additional data derived during a 2 week home CPAP trial to identify factors associated with longer term use of CPAP and compliance.
\end{abstract}

Methods-Following a diagnostic study, 209 patients were offered a CPAP machine for a 2 week home trial. After completing the trial, patients were reassessed and scored their overall satisfaction with CPAP treatment on a five point scale ranging from "much worse" to "much better" and an Epworth score relating to the loan period. Machine run time was recorded from the integral clock. These data were added to those available at diagnosis to construct models indicative of continuing CPAP and average nightly use at 1 year.

Department of Respiratory Medicine, St James's University Hospital, Leeds

LS9 7TF, UK

G Popescu

M Latham

M W Elliott

Department of Medical Statistics V Allgar

Correspondence to: Dr M W Elliott mark.elliott@ gw.sjsuh.northy.nhs.uk

Received 15 May 2000 Returned to authors 15 August 2000 Revised version received 18 May 2001 Accepted for publication 4 June 2001
Results-209 patients were offered the 2 week loan at least a year before June 1999 (90.9\% men, mean (SD) age 51.0 (10.6) years, body mass index (BMI) 34.6 (7.7) $\mathrm{kg} / \mathrm{m}^{2}$, Epworth score 15 (IQR 11-18), apnoea/hypopnoea index (AHI) 38.1 (22.9) events/h). 153 patients $(73.2 \%)$ opted to continue CPAP and 56 declined. One year later data were available for 187 patients; $128(68.5 \%$ on an intention to treat analysis) continued to use the machine with a mean use of 5.0 (2.4) hours/night. A logistic regression model indicated that mean CPAP use during the loan period and the overall satisfaction score accurately defined continuing CPAP and "satisfactory" CPAP use at 1 year. For patients with low machine use and no symptomatic improvement during the loan period, the addition of baseline AHI, baseline Epworth score, and the Epworth score at the end of the loan to the equation identifying factors associated with "satisfactory" CPAP use (mean $>2$ hours/night) improved the value of the model.

Conclusion-Data derived from a 2 week CPAP trial are useful in identifying patients who will comply with CPAP treatment to 1 year. It can be used to identify patients with significant symptomatic disease who will struggle with CPAP and may benefit from additional education and support. High mean hourly use and a high degree of overall satisfaction during the loan period identified patients likely to use CPAP and be compliant with it at 1 year.

(Thorax 2001;56:727-733)

Keywords: sleep apnoea/hypopnoea syndrome; continuous positive airway pressure; home treatment; compliance

The sleep apnoea/hypopnoea syndrome (SAHS) has a prevalence of $2-4 \%$ in the general adult population. ${ }^{1}$ It impairs daytime intellectual and physical function and there is accumulating evidence that it may cause systemic hypertension, cardiovascular, and cerebrovascular disease. ${ }^{2-8}$ Patients with sleep apnoea have been shown to be at increased risk of traffic accidents. ${ }^{9-12}$ In several randomised controlled trials continuous positive airway pressure (CPAP) has been shown to be highly effective in relieving symptoms due to SAHS. ${ }^{13-18}$ Various workers have identified factors which predict acceptance of and compliance with this treatment in patients with SAHS, ${ }^{19-27}$ while others have evaluated strategies for improving them. ${ }^{28}$ In our unit patients with SAHS who are considered for long term home treatment borrow a machine for 2 weeks after a CPAP titration study, giving them the opportunity to try this treatment in their own environment. In this study we evaluate the contribution of data obtained during this 2 week home trial to identify factors associated with long term CPAP use and compliance.

\section{Methods}

PATIENTS

Patients referred with suspected sleep breathing disorders were assessed and most underwent diagnostic sleep studies, usually performed in hospital, using equipment which 
records respiratory but not EEG variables and with automatic analysis (Autoset Sleep Diagnostic system; ResMed UK Ltd, Abingdon, UK or the Densa DMS 200; Ferraris Medical Ltd, Middlesex, UK). Occasionally patients had full polysomnography or oximetry alone, and a small number of studies were carried out at home (Densa Compact; Ferraris Medical and Autoset Portable; ResMed). The Epworth score was recorded at baseline and used as a guide to the severity of sleepiness, while accepting its limitations. ${ }^{29}$

The decision to offer patients a trial of CPAP depended on a balance between the severity of SAHS (based on the apnoea/hypopnoea index (AHI) during the diagnostic study), the patients' symptoms, and their impact upon quality of life. Broadly speaking, patients with significant SAHS (AHI $\geqslant 30$ events/hour) were offered a trial of CPAP whether or not they perceived that they had significant symptoms, whereas patients with AHI $<30$ events/hour were only offered a trial of CPAP if they had symptoms which had an impact on quality of life and daytime function. Other factors such as occupation, miles driven per year, marital disharmony, potential for benefit from other interventions (alcohol avoidance, weight reduction, relief of nasal obstruction), patients' preference and expectation also influenced the decision. CPAP was offered as the first choice treatment before considering mandibular advancement devices.

Patients who accepted the offer of a CPAP trial underwent a CPAP titration study, usually automated (Autoset) but occasionally manual, followed by a 2 week home loan of a CPAP system. They had a pre-loan session with a specialist nurse during which they were fitted with an appropriate mask and head gear and the rationale, benefits, and possible side effects of CPAP were explained again in detail. At the end of the loan period they returned the machine and were reviewed by the nurse specialist. They completed an Epworth score relating to the loan period (tEpworth score) and an in-house five point overall satisfaction score assessing their well being during treatment compared with baseline ("much worse", "worse", "the same", "better", "much better"). The mean use of the machine during the loan period was calculated by dividing the number of hours of use recorded on the integral clock by the number of nights of use.

After completing the loan period, patients had a period of at least 2 weeks without CPAP and were then reviewed in the sleep clinic where they were offered the option of continuing CPAP or not. Occasionally, patients were offered an extension of the 2 week period or a second loan, either because they developed a problem during the loan which compromised their ability to use CPAP (upper respiratory tract infections) or if they had severe symptomatic disease, had struggled with CPAP, and were willing to have another try. During the second trial patients were offered any of the following: a different mask, a humidifier, or a lower starting pressure as deemed appropriate.
For those accepting CPAP a machine was issued and follow up appointments booked for 3-6 months in the sleep clinic and thereafter in a yearly nurse led CPAP users' clinic. Patients were encouraged to contact the nurse specialist if there were problems related to CPAP at any time. At the yearly appointment they were weighed and completed an Epworth score and the five point overall satisfaction score. The mean use of the machine was calculated by dividing the recorded hours of use by the number of days since the last reading. Patients using the CPAP machine for more than 2 hours/night on average were considered to have "satisfactory" levels of use. Those with low machine use and/or poor symptom control had further input which included change of mask type, addition of a humidifier, adjustment of CPAP pressure, or further education.

DATA RECORDING

Since 1995 details on all patients undergoing sleep studies in our department have been recorded in a series of relational databases (Lotus Approach version 3). These contain patient details, the data from each diagnostic or titration study, from each CPAP loan, and from the yearly CPAP users' clinic. For the purpose of this study all data were anonymised. The study was approved by the St James's and Seacroft University Hospitals NHS Trust ethical committee.

STATISTICAL ANALYSIS

For statistical comparisons between the groups the Student's $t$ test was used for age and Mann-Whitney tests for BMI, Epworth score, AHI, pressure, and machine usage. $\chi^{2}$ tests were used for comparisons of categorical data-for example, sex and five point overall satisfaction score. Relationships between variables were investigated using Spearman correlations. Logistic regression analysis (forward stepwise conditional method) was used to construct models that could be used to identify patients continuing to use CPAP and long term "satisfactory" levels of compliance. A p value of $<0.05$ was considered significant. SPSS for Windows (Version 8, SPSS, Chicago) was used for statistical analysis.

\section{Results}

Between June 1995 and June 1998209 patients who were considered for long term CPAP treatment $(90.9 \%$ mem, mean (SD) age 51.0 (10.6) years, BMI $34.6(7.7) \mathrm{kg} / \mathrm{m}^{2}$, median Epworth score 15 (IQR 11-18), and AHI 38.1 (22.9) events/hour) had a CPAP titration study and a 2 week home trial of CPAP was offered to all them. The outcome for the process is summarised in fig 1. Following the CPAP titration study $196(93.8 \%)$ tried CPAP at home (fig 1-A). After completing the loan period, 153 patients $(73.2 \%$ on an intention to treat basis) opted to continue CPAP at home (fig 1-B) and 56 refused (fig 1-C). Of the latter group, eight $(3.8 \%)$ refused the loan after the titration study and five $(2.4 \%)$ took the CPAP machine home but never used it. 


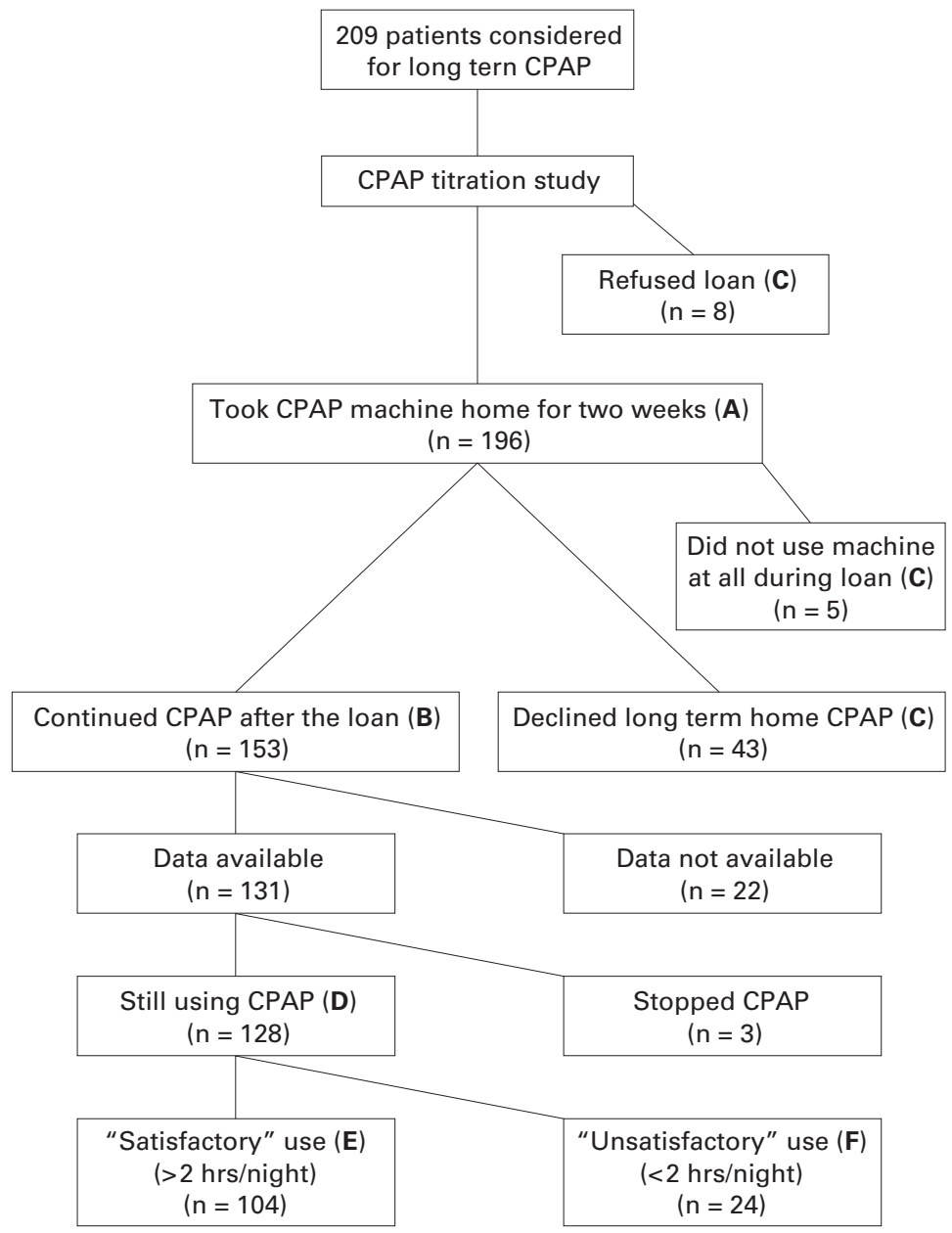

Figure 1 Flow diagram showing the groups of patients used for comparisons.

Some patients did not complete the five point symptom scale or the Epworth score scale at the end of the loan, while others (especially those declining home CPAP) returned the CPAP machines through relatives or friends. The non-response rate was $1.3 \%(n=2)$ in those who opted for home CPAP and $14.2 \%$ $(n=8)$ among those who declined long term CPAP. Patients who opted for home CPAP (fig 1-B) had a higher baseline AHI (40.4 (23.4) v 31.8 (20.6) events/hour, $\mathrm{p}=0.016)$ and $\mathrm{BMI}$ (35.7 (7.9) v $\left.31.7(6.5) \mathrm{kg} / \mathrm{m}^{2}, \mathrm{p}<0.001\right)$, a lower Epworth score at the end of the loan (tEpworth score 5 (IQR 3-9) v 11 (IQR 7-14), $\mathrm{p}<0.001)$, a larger fall in their Epworth score between baseline and the end of the CPAP loan (dEpworth score 8 (IQR 5-12) v 2 (IQR 0-5), $\mathrm{p}<0.001$ ), greater improvement in symptoms as rated by the five point overall satisfaction score (table 1), a higher CPAP pressure (8.9

Table 1 Differences expressed in the overall satisfaction score between patients who opted to continue the CPAP treatment after the loan and those who declined it

\begin{tabular}{llll}
\hline & $\begin{array}{l}\text { CPAP declined } \\
(n=56)\end{array}$ & $\begin{array}{l}\text { CPAP accepted } \\
(n=153)\end{array}$ & $p$ value \\
\hline Overall satisfaction score & $2(100 \%)$ & - & $<0.01$ \\
Much worse & $9(100 \%)$ & - & \\
Worse & $23(82 \%)$ & $5(18 \%)$ & \\
Same & $14(2 \%)$ & $49(78 \%)$ & \\
Better & - & $97(100 \%)$ & \\
Much better & & & \\
\hline
\end{tabular}

Results presented as number of patients (\% declining/accepting the treatment after the loan).
(2.1) $\left.v 8.2(2.5) \mathrm{cm} \mathrm{H}_{2} \mathrm{O}, \mathrm{p}=0.049\right)$, and used the machine more during the loan period (5.5 (1.9) $v 2.6$ (2.3) hours/night, $\mathrm{p}<0.001$ ) than those who did not. Fourteen patients who subsequently declined CPAP rated themselves as "better" following the loan. Five patients who considered themselves "the same" at the end of the loan subsequently opted for home CPAP, usually because on reflection, having experienced CPAP and then felt again what it was like to be without treatment, decided that the advantages outweighed the disadvantages.

Data were available for 187 patients at 1 year. Due to changes in arrangements for funding, 15 patients were transferred to other centres and seven were lost to follow up despite repeated attempts to contact them. 128 patients used the machine for more than 12 months (fig 1-D); 59 (31.5\%) had declined CPAP either from the outset (eight before and 48 after the CPAP loan) or during the first year of use $(n=3) ; 68.5 \%$ of patients offered a trial of CPAP (intention to treat basis) and $97.7 \%$ of patients who opted for CPAP after their loan continued with CPAP at 1 year. The mean CPAP use decreased from 5.6 (1.8) hours/ night at the end of the 2 week loan to 5.0 (2.4) hours/night at 1 year $(p=0.001)$. The median Epworth score increased from 5 (IQR 3-9) at the end of the loan to 7 (IQR 4-12) at 1 year $(\mathrm{p}<0.001)$.

The characteristics of patients continuing to use CPAP for more than 1 year and of those who did not are shown in table 2 . Continued use at 1 year was associated with a higher baseline BMI, male sex, higher baseline AHI, greater fall in AHI with CPAP, a lower Epworth score at the end of the CPAP loan period, and a larger fall in Epworth score from diagnosis to the end of the loan period. Patients who rated themselves as "better" or "much better", had a higher CPAP pressure, and used the machine more during their loan were more likely to continue CPAP at 1 year.

While patients were encouraged to use their CPAP throughout each night, it is not known whether this was necessary and how many hours of use per night were needed for relief of daytime symptoms. Of our patients, $81.3 \%$ had a mean nightly use of $>2$ hours, $76.6 \%$ of $>3$ hours, and $68.8 \%$ of $>4$ hours. In our unit a mean nightly use of $>2$ hours is considered to be "satisfactory" (fig 1-E). Patients with "satisfactory" use at 1 year (fig 1-E) had a significantly higher CPAP use during the loan (6 (1.5) v 3.9 (1.9) hours, $\mathrm{p}<0.001)$, a greater change in the Epworth score with CPAP (9 $(8-10)$ v 7 (3.5-8), $\mathrm{p}=0.02)$, and a greater number of tEpworth score values below 12 than those with long term machine use of $<2$ hours/night (80 patients $v 7$ patients; fig $1-F)$. The Epworth score after 1 year of treatment was significantly lower for patients with "satisfactory" use, and more patients (78.4\%) who used their machine for $>2$ hours/ night on average had an Epworth score within the normal range compared with only $35 \%$ of those with mean use of $<2$ hours/night $(p<0.001)$. There was no difference, however, between the two groups in their perception of 
Table 2 Characteristics of patients continuing to use CPAP at 1 year compared with those refusing the treatment during the first 12 months

\begin{tabular}{|c|c|c|c|}
\hline & $\begin{array}{l}\text { CPAP declined or } \\
\text { stopped }(n=59)\end{array}$ & $\begin{array}{l}\text { CPAP continued } \\
(n=128)\end{array}$ & $p$ value \\
\hline Age (years) & $52.37(12.8)$ & $50.39(9.6)$ & NS \\
\hline $\mathrm{BMI}\left(\mathrm{kg} / \mathrm{m}^{2}\right)$ & $31.92(6.7)$ & $35.79(7.4)$ & $<0.001$ \\
\hline \multicolumn{4}{|l|}{ Sex } \\
\hline Male ${ }^{\star}$ & $50 \quad(29.4 \%)$ & $(70.6 \%)$ & 0.047 \\
\hline Female ${ }^{\star}$ & $9 \quad(53.0 \%)$ & $(47.0 \%)$ & \\
\hline bAHI & $32.14(20.7)$ & $41.49(23.9)$ & 0.013 \\
\hline$<15^{\star}$ & $14 \quad(50.0 \%)$ & $14 \quad(50.0 \%)$ & \\
\hline $15-29^{\star}$ & $(34.0 \%)$ & $(65.9 \%)$ & 0.049 \\
\hline$\geqslant 30^{\star}$ & $29 \quad(26.1 \%)$ & $82 \quad(73.8 \%)$ & \\
\hline tAHI & $9.91(9.42)$ & $8.81(6.98)$ & NS \\
\hline dAHI & $22.22(21.50)$ & $32.47(23.95)$ & 0.006 \\
\hline \multicolumn{4}{|l|}{ bEpworth score } \\
\hline Median (IQR) & $(10-17)$ & $(12-19)$ & NS \\
\hline$\leqslant 12^{\star}$ & $(36.0 \%)$ & $(63.9 \%)$ & NS \\
\hline$>12^{\star}$ & $(28.2 \%)$ & $(71.7 \%)$ & \\
\hline \multicolumn{4}{|l|}{ tEpworth score } \\
\hline Median (IQR) & $15.5(6-14)$ & $(3-9)$ & $<0.001$ \\
\hline$\leqslant 12^{\star}$ & $31 \quad(21.3 \%)$ & $(78.6 \%)$ & \\
\hline$>12^{\star}$ & $19 \quad(57.5 \%)$ & $(42.4 \%)$ & $<0.001$ \\
\hline \multicolumn{4}{|l|}{ dEpworth score } \\
\hline Median (IQR) & $(0-6)$ & $(5-13)$ & $<0.001$ \\
\hline \multicolumn{4}{|l|}{ Overall satisfaction score } \\
\hline Much worse & $(100 \%)$ & 0 & \\
\hline Worse ${ }^{\star}$ & $(100 \%)$ & 0 & \\
\hline Same^ & $(85.1 \%)$ & $(14.8 \%)$ & $<0.001$ \\
\hline Better ${ }^{\star}$ & $(31.3 \%)$ & $(68.6 \%)$ & \\
\hline Much better & $1 \quad(1.2 \%)$ & $88 \quad(98.8 \%)$ & \\
\hline CPAP pressure & $8.27(2.42)$ & $9.07(2.08)$ & 0.029 \\
\hline CPAP use during loan & $2.63(2.28)$ & $5.63(1.83)$ & $<0.001$ \\
\hline
\end{tabular}

Results presented as mean (SD) unless otherwise stated.

${ }^{\star}$ Number of patients (\% of declining/accepting treatment after the loan).

$\mathrm{BMI}=$ body mass index; bAHI, tAHI, dAHI = apnoea/hypopnoea index at baseline, during titration study, and difference between titration study and baseline, respectively; bEpworth, tEpworth, $\mathrm{dEpworth}=$ Epworth score at baseline, during the 2 week loan, and difference between the 2 week loan value and baseline value, respectively; NS = non-significant; IQR = interquartile range.

how their symptoms had changed from before starting CPAP. The figure of 2 hours/night is arbitrary, but a cut off of 3 or 4 hours/night made no difference to the results.

The various data available at baseline, after the CPAP titration study, and at the end of the loan were analysed to find which factors were significant at explaining acceptance of CPAP at the end of the loan, continuing use, and "satisfactory" use at 1 year. No continuous data correlation proved to be strongly related to continuing use at 1 year. The mean nightly use at 1 year was significantly but weakly correlated with the average CPAP use during the loan period $(r=0.299, \mathrm{p}<0.001)$, the tEpworth score $(r=-0.299, \mathrm{p}=0.003)$, and the Epworth score at 1 year $(r=-0.201, \mathrm{p}<0.001)$. The logistic regression models obtained including data available by the end of the titration study were not helpful in identifying which patients would use CPAP long term. Baseline parameters included were BMI and sex in the model of acceptance after the loan, and BMI and baseline AHI in the models associated with continuing CPAP use and "satisfactory" CPAP use at 1 year

When the data available at the end of the loan period were included the models had improved classification. In the logistic models mean CPAP use during the loan and the self-reported overall satisfaction score after the trial were factors for continued CPAP use (classified $76 \%$ of those who did not continue and $95 \%$ of those who continued). For "satisfactory" CPAP use at 1 year only mean CPAP use during the loan was significant in the model, with $67.6 \%$ of those who did not have "satisfactory" use and $94.2 \%$ of those who did have "satisfactory" use being correctly classified. For each hour of use during the loan, the likelihood of continuing CPAP at 1 year increased 1.53 times (95\% CI 1.06 to 1.71 ) and "satisfactory" use 1.49 times (95\% CI 1.19 to 1.86). With a cut off of 2 hours/night CPAP use during the 2 week loan period, the odds ratio for continuing use at 1 year was 17.8 (95\% CI 7.0 to $45.7, \mathrm{p}<0.001)$. Moreover, patients reporting themselves to be "much better" after the CPAP trial were three times more likely than those feeling "better" and many times more likely than those not improved to accept CPAP long term and to have "satisfactory" use. The addition of baseline AHI, baseline Epworth score, and tEpworth score to the equation predicting "satisfactory" CPAP use improved the utility of the model. This suggests that, for patients with low CPAP use during the loan and no improvement in symptoms, a high diagnostic AHI and bEpworth score and a low tEpworth score increase the probability of long term acceptance and compliance.

\section{Discussion}

In this study we have evaluated the usefulness of a 2 week trial for identifying patients who would use CPAP long term and be compliant with it.

The percentage of patients initially accepting and then continuing CPAP at 1 year was similar to that in other studies, which suggests that our patients and practice were comparable to others. A high proportion of patients tried CPAP at home after the titration night $(93.7 \%)$ and continued long term after completing the loan period $(73.2 \%)$. In our study the rate of continuing use at 1 year was $68.4 \%$ of all patients to whom treatment was recommended, $71.7 \%$ of those who underwent a CPAP trial, and $97.7 \%$ of those who opted to continue the treatment afterwards. These figures are similar to the $95.5 \%$ of patients accepting CPAP after titration and $84 \%$ continuing to use it during the first 12 months of treatment reported by McArdle and colleagues. ${ }^{20}$ In their study the proportion of patients lost to follow up was very low $(0.8 \%)$ whereas in our study $10.5 \%$ of the patients ( $7.1 \%$ transferred and $3.4 \%$ lost to follow up) were not included in the analysis. All these patients initially accepted long term treatment and many of them probably continued treatment in other centres. Previous reports indicated values of $72-79 \%$ for continuing use at 1 year, but the analyses were not performed on an "intention to treat" basis. ${ }^{22}{ }^{23}$ In the study by Krieger $e t a l^{23}$ the rate of use at the end of the first year of treatment for selected patients with AHI $>15$ was $79 \%$, but these patients themselves represented only $79 \%$ of the patients to whom treatment had been recommendedequivalent to a rate of $62.4 \%$ on an intention to treat analysis.

The percentage of patients with SAHS accepting long term CPAP treatment and continuing its use at potentially effective levels is comparable with the adherence and compliance with various treatments for other respiratory diseases. Compliance rates of $48-67 \%$ 
have been reported for inhaled therapy in asthma and COPD. ${ }^{31-33}$ Similar values have been found for long term oxygen therapy in chronic respiratory failure (50-65\%), ${ }^{34}{ }^{35}$ nebulisers in COPD (50-57\%), ${ }^{36}$ and successfully completed treatments in tuberculosis $(50-60 \%) .^{38} 39$

There is no uniform definition of "compliance" in the literature but we, as others, ${ }^{20} 40$ calculated the mean nightly use by dividing the machine run time by the number of days between two readings. Our calculated mean use at 1 year was 5.0 hours/night $(70.4 \%$ of patients had a mean use $>4$ hours $/$ night, $78.4 \%$ $>3$ hours/night, and $82.4 \%>2$ hours/night), similar to data from other studies in which mean values between 2.8 and 4.3 hours/night were achieved. ${ }^{19}{ }^{40} 41$ In studies reporting follow up for longer than 1 year, compliance ranged from 5 hours/night with $74 \%$ using it for $>4$ hours/night to 5.7 hours/night with $76 \%$ using it for $>3.7$ hours/night. ${ }^{2022}{ }^{23}$ In the study by Krieger et $a l^{23}$ the high mean use might be due to the fact that all patients had an AHI of $>15$. The best reported mean use (5.7 hours/ night) was achieved with intensive support and a special educational programme during the first year of use ${ }^{20}{ }^{28}$; however, because of the large number of patients coming forward for treatment, this strategy is unlikely to be practical or cost effective in most centres. The finding that our data are similar to those reported by others suggests that the approach we used may be helpful in other units, notwithstanding the fact that local practice will vary from centre to centre.

The group declining CPAP treatment had a mean AHI of 31.8 events/hour, a median baseline Epworth score of 15, and many patients had severe disease. Usage during the loan period was low and the improvement obtained in $\mathrm{AHI}$ and Epworth score with CPAP was less than that seen in the patients who opted for long term treatment. We offered second loans to patients who had a high AHI and were symptomatic. Thirteen patients completed a second loan and, although the mean use improved in this group from 1.7 hours/night during the first loan to 3.2 hours/night during the second loan, only five then accepted long term treatment. Patients with low machine use during the first loan might need alternative strategies including "smart" CPAP and more intensive support in any subsequent CPAP trials. Women have recently been reported to have a lower acceptance rate for treatment. ${ }^{20}$ We found a significant difference in continuing CPAP use at 1 year between men and women in our group $(70.6 \% v 47.1 \%, \mathrm{p}=0.047)$. This finding may be a coincidence but it suggests that women might need special attention.

A slightly higher CPAP pressure was associated with a higher acceptance rate and increased CPAP use. This has been seen in other studies. ${ }^{20}{ }^{23}$ The differences in mean CPAP pressure between acceptors and nonacceptors are small but significant $\left(1 \mathrm{~cm} \mathrm{H}_{2} \mathrm{O}\right.$ in our study and the study by Krieger et $a l^{23}$ ). McArdle et $a l^{20}$ showed that continued CPAP use was 1.53 times $(p=0.002)$ more likely at a pressure of $>8 \mathrm{~cm} \mathrm{H}_{2} \mathrm{O}$. They suggested that the relationship between pressure and use might result from the covariance of CPAP pressure and baseline AHI levels. We found a correlation between pressure and baseline AHI $(r=0.371, \quad \mathrm{p}<0.001)$ which supports this theory. A mean pressure of $8 \mathrm{~cm} \mathrm{H}_{2} \mathrm{O}$ may also be too low to improve AHI and symptoms satisfactorily; we found significant correlations between CPAP pressure and tEpworth score $(r=-0.243, \quad \mathrm{p}<0.001), \quad$ dEpworth score $(r=0.210, \mathrm{p}<0.001)$, and dAHI $(r=0.358$, $\mathrm{p}<0.001)$

Various parameters have been found to correlate with long term use of CPAP or with compliance in other studies. They include age, BMI, AHI, snoring history, polysomnographic results, respiratory function tests, daytime oxygen saturation, $\mathrm{SaO}_{2}$ during non-REM sleep, and night to night variability during the initial period of CPAP use. ${ }^{19-25} 27$ Several studies $^{202123}{ }^{26}$ have indicated a significant correlation between long term CPAP use and daytime sleepiness, and one study showed that long term daily use correlated with treatment induced improvements in AHI, hypersomnia scores, and oxygen saturation during sleep. ${ }^{24}$ Although significant, these correlations were weak with $r$ values of less than 0.50 . We also found a weak correlation between the mean use of the machine at 1 year and the mean use of the machine during the loan $(r=0.299$, $\mathrm{p}<0.001)$ and the Epworth score after the loan $(r=0.299, \mathrm{p}=0.003)$.

Meslier and colleagues ${ }^{42}$ in a large French survey of long term CPAP have shown that the perceived health (evaluated by the Nottingham Health Profile) in patients with SAHS is significantly related to the improvement of symptoms, overall satisfaction, and objective compliance with CPAP. We used a simple assessment of the patient's overall satisfaction with CPAP in comparison with how they were before starting treatment. The scale reflects the balance between any benefits in terms of a reduction in symptoms of SAHS by CPAP (which is also measured by the difference between baseline and treatment Epworth scores) and the disadvantages of CPAP to the patient and his or her family. This simple scale proved to be highly discriminative in many comparisons we performed (tables 1 and 2).

From the data available following the diagnostic study it was not possible to construct an acceptable model for continuing use at 1 year, but data derived from the 2 week loan (overall symptom change with CPAP and mean use during the loan) defined acceptance of long term treatment and continuing and "satisfactory" use at 1 year with reasonable precision. Analysis of the correlation between CPAP use during the 2 week loan period ( $<2$ hours/night $v>2$ hours/night) and the continuing use at 1 year gave an odds ratio for continuing use of 17.8 (95\% CI 7.0 to $45.7, \mathrm{p}<0.001)$. This is very similar to the findings of McArdle et al who, using a different statistical approach, reported hazard ratios of continuing use of CPAP long term of 13.8 (95\% CI 8.9 to 21.5 , $\mathrm{p}<0.001$ ) based on CPAP use over the first 3 
months. ${ }^{20}$ Patients who were the same or worse during the loan were likely to refuse CPAP or not use it long term, whereas patients who felt "much better" after 2 weeks of treatment were more likely to comply with long term treatment. The rates for continuing use at 1 year and for use of $>2$ hours/night long term were $14.8 \%$ and $0 \%$ for patients feeling "the same", $68.6 \%$ and $82.9 \%$ for those who felt "better", and $98.9 \%$ and $85.2 \%$ for those feeling "much better" after the loan period (table 2).

Thresholds of "satisfactory" use have been defined differently. Engleman et $a l^{40}$ showed improvement in cognitive function, mood, symptom scores, and effective daytime sleepiness with a mean use of $>3.7$ hours/night. However, there are no data available on the minimum use that is effective and no agreement on cut off values for stopping treatment because of non-compliance. Different centres ask for the return of the CPAP machine if use is less than 1 hour/night despite reinforced education, ${ }^{23} 2$ hours/night, ${ }^{20} 4.5$ hours/night, ${ }^{22}$ or 5 hours/night. ${ }^{24}$ We consider patients with a mean use of more than 2 hours/night to have "satisfactory" compliance; $78.4 \%$ of "compliant" patients had an Epworth score below 12 after long term treatment compared with 35\% for those with a mean use of less than 2 hours/ night, which suggests that this is a reasonable cut off. The mean use over 1 year correlated with the Epworth score at 1 year $(r=-0.201$, $\mathrm{p}<0.001$ ), suggesting that benefit from CPAP is at least in part related to the amount that the machine is used. We found that CPAP use at 1 year was less than that at the end of the loan period and there was an increase in the Epworth score. This suggests that reinforcement of the importance of maintaining a high level of machine use will improve symptomatic benefit. However, there was no difference between "satisfactory" and "unsatisfactory" users in their rating of the change in symptoms on the five point scale, suggesting a possible placebo effect which has been seen in a trial using sham CPAP. ${ }^{13}$ "Satisfactory" use can be mathematically modelled by a logistic regression model which includes both baseline data (AHI and Epworth score) and data obtained during the 2 week loan (mean use of the machine, tEpworth score, and five point overall satisfaction score).

The identification at an early stage of patients who are unlikely to continue CPAP is important. Firstly, untreated patients will experience continuing symptoms which are potentially amenable to improvement by CPAP. ${ }^{13-18}$ Secondly, there is increasing evidence that SAHS is associated with other adverse health effects and, although it is not proved that CPAP influences these and while CPAP prescription would not be considered primarily with these outcomes in mind, a reduction in other morbidities is an important secondary benefit from CPAP. However, perhaps the major concern relates to driving and the implications of untreated symptomatic SAHS for holding a driver's licence. ${ }^{10-12}$ A 2 week loan may be useful in identifying which patients need more intense input and/or alternative CPAP devices.

Despite the limitations of a retrospective analysis, this study suggests that patients with SAHS who may be reluctant to use CPAP long term can be identified in the early stages of treatment. A 2 week CPAP loan provides useful information on patient satisfaction with treatment and his or her compliance measured by mean machine use. In our experience these two parameters are important for identifying patients who will be compliant with CPAP and continue to use it. A combination of the level of overall satisfaction with CPAP, a simple five point scale, and machine run time during the trial is associated with good compliance and continuing use at 1 year. This is further refined by the addition of AHI and Epworth score at baseline and the Epworth score at the end of the 2 week trial.

1 Young T, Palta M, Dempsey J, et al. The occurrence of leep-disordered breathing among middle-aged adults. $N$ Engl f Med 1993;328:1230-5.

2 Peker Y, Kraiczi H, Hedner J, et al. An independent association between obstructive sleep apnoea and coronary artery disease: accept it, with some revision. Eur Respir 7 1999;14:179-84.

3 Lavie P, Herer P, Hoffstein V. Obstructive sleep apnoea syndrome as a risk factor for hypertension: population study. BMF 2000;320:479-82.

4 Bassetti C, Aldrich MS. Sleep apnea in acute cerebrovascular diseases: final report on 128 patients. Sleep 1999;22: lar disease $217-23$.

5 Lindberg E, Janson C, Svardsudd K, et al. Increased mortality among sleepy snorers: a prospective population based study. Thorax 1998;53:631-7.

6 Brooks D, Horner RL, Kozar LF, et al. Obstructive sleep apnea as a cause of systemic hypertension. Evidence from a canine model. F Clin Invest 1997;99:106-9.

7 Keyl C, Lemberger P, Rodig G, et al. Changes in cardiac autonomic control during nocturnal repetitive oxygen desaturation episodes in patients with coronary artery disease. F Cardiovasc Risk 1996;3:221-7.

8 Coy TV, Dimsdale JE, Ancoli-Israel S, et al. The role of sleep-disordered breathing in essential hypertension. Chest 1996;109:890-5.

9 Krieger J, Meslier N, Lebrun T, et al. Accidents in obstructive sleep apnea patients treated with nasal continuous positive airway pressure: a prospective study. The Working positive airway pressure: a prospective study. The Working Association Nationale de Traitement a Domicile des InsufAssociation Nationale de Traitement a Domicile
fisants Respiratoires. Chest 1997;112:1561-6.

10 Young T, Blustein J, Finn L, et al. Sleep-disordered breathing and motor vehicle accidents in a population-based sample of employed adults. Sleep 1997;20:608-13.

11 Teran-Santos J, Jimenez-Gomez A, Cordero-Guevara J. The association between sleep apnea and the risk of traffic accidents. Cooperative Group Burgos-Santander. N Engl F Med 1999;340:847-51.

12 Barbe F, Pericas J, Munoz A, et al. Automobile accidents in patients with sleep apnea syndrome. An epidemiological and mechanistic study. Am $f$ Respir Crit Care Med 1998;158:18-22.

13 Jenkinson C, Davies RJ, Mullins R, et al. Comparison of therapeutic and subtherapeutic nasal continuous positive airway pressure for obstructive sleep apnoea: a randomised prospective parallel trial. Lancet 1999;353:2100-5.

prospective parallel trial. Lancet 1999;353:2100-5.
14 Ballester E, Badia JR, Hernandez L, et al. Evidence of the effectiveness of continuous positive airway pressure in the treatment of sleep apnea/hypopnea syndrome. Am 7 Respir treatment of sleep apnea/hypopnea
Crit Care Med 1999;159:495-501.

15 Engleman HM, Kingshott RN, Wraith PK, et al. Randomized placebo-controlled crossover trial of continuous positive airway pressure for mild sleep apnea/hypopnea positive airway pressure for mild sleep apnea/hypopn
syndrome. Am f Respir Crit Care Med 1999;159:461-7.

16 Engleman HM, Martin SE, Kingshott RN, et al. Randomised placebo controlled trial of daytime function after continuous positive airway pressure (CPAP) therapy for the sleep apnoea/hypopnoea syndrome. Thorax 1998;53:3415.

17 Engleman HM, Martin SE, Deary IJ, et al. Effect of CPAP therapy on daytime function in patients with mild sleep apnoea/hypopnoea syndrome. Thorax 1997;52:114-9.

18 Engleman HM, Martin SE, Deary IJ, et al. Effect of continuous positive airway pressure treatment on daytime function in sleep apnoea/hypopnoea syndrome. Lancet 1994:343:572-5.

19 Reeves-Hoche MK, Meck R, Zwillich CW. Nasal CPAP: an objective evaluation of patient compliance. Am $\mathcal{F}$ Respir Crit Care Med 1994;149:149-54.

20 McArdle N, Devereux G, Heidarnejad H, et al. Long-term use of CPAP therapy for sleep apnea/hypopnea syndrome. Am $\mathcal{F}$ Respir Crit Care Med 1999;159:1108-14. 
21 Rauscher H, Popp W, Wanke T, et al. Acceptance of CPAP therapy for sleep apnea. Chest 1991;100:1019-23.

22 Pieters T, Collard P, Aubert G, et al. Acceptance and longterm compliance with nCPAP in patients with obstructive sleep apnoea syndrome. Eur Respir F 1996;9:939-44.

23 Krieger J, Kurtz D, Petiau C, et al. Long-term compliance with CPAP therapy in obstructive sleep apnea patients and in snorers. Sleep 1996;19:S136-43.

24 Meurice JC, Dore P, Paquereau J, et al. Predictive factors of long-term compliance with nasal continuous positive airway pressure treatment in sleep apnea syndrome. Chest 1994;105:429-33.

25 Rolfe I, Olson LG, Saunders NA. Long-term acceptance of continuous positive airway pressure in obstructive sleep apnea. Am Rev Respir Dis 1991;144:1130-3.

26 Waldhorn RE, Herrick TW, Nguyen MC, et al. Long-term compliance with nasal continuous positive airway pressure therapy of obstructive sleep apnea Chest 1990;97:33-8.

27 Weaver TE, Kribbs NB, Pack AI, et al. Night-to-night variability in CPAP use over the first three months of ability in CPAP use over the

28 Hoy CJ, Vennelle $\mathrm{M}$, Kingshott $\mathrm{RN}$, et al. Can intensive support improve continuous positive airway pressure use in patients with the sleep apnea/hypopnea syndrome? $A m \mathcal{F}$ Respir Crit Care Med 1999;159:1096-100.

29 Johns MW. A new method for measuring daytime sleepiness: the Epworth sleepiness scale. Sleep 1991;14 $540-5$

30 Loube DI, Gay PC, Strohl KP, et al. Indications for positive airway pressure treatment of adult obstructive sleep apnea patients: a consensus statement. Chest 1999;115:863-6.

31 Cochrane GM. Therapeutic compliance in asthma: its magnitude and implications. Eur Respir f 1992;5:122-4.

32 Bosley CM, Fosbury JA, Cochrane GM. The psychological factors associated with poor compliance with treatment in asthma. Eur Respir 7 1995;8:899-904.

33 Rand CS, Nides M, Cowles MK, et al. Long-term metereddose inhaler adherence in a clinical trial. The Lung Health
Study Research Group. Am $\mathcal{f}$ Respir Crit Care Med 1995; 152:580-8.

34 Howard P, Waterhouse JC, Billings CG. Compliance with long-term therapy by concentrator. Eur Respir $\mathcal{F}$ 1992;5: 128-9.

35 Ringbaek T, Lange P, Viskum K. Compliance with LTOT and consumption of mobile oxygen. Respir Med 1999;93: $333-7$.

36 Turner J, Wright E, Mendella L, et al. Predictors of patient adherence to long-term home nebulizer therapy for COPD. The Intermittent Positive Pressure Breathing (IPPB) Study Group. Chest 1995;108:394-400.

37 Corden ZM, Bosley CM, Rees PJ, et al. Home nebulized therapy for patients with COPD: patient compliance with treatment and its relation to quality of life. Chest 1997;112: 1278-82.

38 Zwarenstein M, Schoeman JH, Vundule C, et al. Randomised controlled trial of self-supervised and directly observed treatment of tuberculosis. Lancet 1998;352:1340 3.

39 Wobeser W, Yuan L, Naus M. Outcome of pulmonary tuberculosis treatment in the tertiary care setting, Toronto 1992/93. Tuberculosis Treatment Completion Study Group. Can Med Assoc f 1999;160:789-94.

40 Engleman HM, Martin SE, Douglas NJ. Compliance with CPAP therapy in patients with the sleep apnoea/hypopnoea syndrome. Thorax 1994:49:263-6.

41 Kribbs NB, Pack AI, Kline LR, et al. Objective measurement of patterns of nasal CPAP use by patients with obstructive sleep apnea. Am Rev Respir Dis 1993;147:88795

42 Meslier N, Lebrun T, Grillier-Lanoir V, et al. A French survey of 3225 patients treated with CPAP for obstructive sleep apnoea: benefits, tolerance, compliance and quality of life. Eur Respir f 1998;12:185-92.

\title{
1st Asia Pacific Forum on Quality Improvement in Health Care
}

\author{
Three day conference
}

\section{Wednesday 19 to Friday 21 September 2001 \\ Sydney, Australia}

We are delighted to announce this forthcoming conference in Sydney. Authors are invited to submit papers (call for papers closes on Friday 6 April), and delegate enquiries are welcome.

The themes of the Forum are:

- Improving patient safety

- Leadership for improvement

- Consumers driving change

- Building capacity for change: measurement, education and human resources

- The context: incentives and barriers for change

- Improving health systems

- The evidence and scientific basis for quality improvement.

Presented to you by the BMJ Publishing Group (London, UK) and Institute for Healthcare Improvement (Boston, USA), with the support of the the Commonwealth Department of Health and Aged Care (Australia), Safety and Quality Council (Australia), NSW Health (Australia), and Ministry of Health (New Zealand).

For more information contact: quality@bma.org.uk or fax +44 (0)20 73836869 